\title{
Sigma Receptor 1 Is Preferentially Involved in Modulation of N-Methyl-D-Aspartate Receptor-Mediated Light-Evoked Excitatory Postsynaptic Currents in Rat Retinal Ganglion Cells
}

\author{
Xin-Jun Zhang Lei-Lei Liu Yi Wu Shi-Xiang Jiang Yong-Mei Zhong \\ Xiong-Li Yang \\ Institute of Neurobiology, Institutes of Brain Science and State Key Laboratory of Medical Neurobiology, \\ Fudan University, Shanghai, China
}

\section{Key Words}

Sigma receptor $1 \cdot$ NMDA receptor $\cdot$ AMPA receptor Neurotransmission $\cdot$ Retina $\cdot$ Ganglion cell $\cdot$ Excitatory postsynaptic currents

\begin{abstract}
Using patch-clamp whole-cell recording, we investigated how activation of the sigma receptor $1(\sigma R 1)$ modulates light-evoked excitatory postsynaptic currents (eEPSCs) of ganglion cells (GCs) in rat retinal slice preparations. Bath application of the $\sigma R 1$ agonist SKF10047 (SKF) suppressed Nmethyl-D-aspartate (NMDA) receptor-mediated eEPSCs at different holding potentials in ON, OFF and ON-OFF GCs, and the effects were blocked when the preparations were preincubated with the $\sigma \mathrm{R} 1$ antagonist BD1047. In contrast, SKF had no effects on $\alpha$-amino-3-hydroxy-5-methyl-4-isoxazolepropionic acid (AMPA) receptor-mediated eEPSCs of these GCs. Furthermore, application of SKF did not affect AMPA receptor-mediated miniature EPSCs of GCs, suggesting that activation of $\sigma \mathrm{R} 1 \mathrm{did}$ not change the release of glutamate from bipolar cells. These results suggest that $\sigma \mathrm{R} 1$ may be involved in the regulation of output signaling of GCs by preferentially modulating NMDA receptor-mediated eEPSCs of these retinal neurons.
\end{abstract}

Copyright $\odot 2011$ S. Karger AG, Basel

\section{KARGER}

Fax +4161306 1234

E-Mail karger@karger.ch

www.karger.com
(C) 2011 S. Karger AG, Basel

1424-862X/11/0192-0110\$38.00/0

Accessible online at:

www.karger.com/nsg

\section{Introduction}

Sigma receptor $(\sigma \mathrm{R})$ is a distinct pharmacological entity, representing unique nonopiate, nonphencyclidine binding sites in mammalian nervous systems [1]. $\sigma \mathrm{R}$ was originally classified into three subtypes $(\sigma \mathrm{R} 1, \sigma \mathrm{R} 2$ and $\sigma \mathrm{R} 3)[2,3]$, but $\sigma \mathrm{R} 3$ may be a subclass of the brain histamine $\mathrm{H}_{1}$ receptor [4]. $\sigma \mathrm{R} 1$ has been implicated in various physiological and pathological processes in the central nervous system [for a review, see 5]. In the mammalian retina, $\sigma \mathrm{R} 1 \mathrm{mRNA}$ and protein are expressed in neural elements $[6,7]$. Specifically, in the rat retina it was previously shown that $\sigma \mathrm{R} 1$ is present in horizontal cells, several subtypes of amacrine cells and almost all ganglion cells (GCs) [6]. Much work has demonstrated the efficacy of $\sigma \mathrm{R} 1$ ligands in the protection of retinal neurons [8-12]. For instance, the $\sigma \mathrm{R} 1$ agonist Pre-084 inhibits the expression of the tumor necrosis factor-related apoptosis-inducing ligand (TRAIL), which mediates the toxic effect of amyloid $\beta$ [11], and $\sigma R 1$ agonists antagonize the excitotoxicity induced by glutamine/N-methyl-D-aspartate (NMDA) in GCs [8-10, 12]. Furthermore, our recent study suggests a neuromodulatory role of $\sigma \mathrm{R} 1$ in the retina by showing that activation of this receptor suppresses NMDA receptor-mediated currents of pharmacological-

Dr. Xiong-Li Yang and Yong-Mei Zhong

Institute of Neurobiology, Fudan University

138 Yixueyuan Road, Shanghai 200032 (China)

Tel. +862164221975

E-Mail xlyang@fudan.edu.cn and ymzhong@fudan.edu.cn 
ly isolated rat GCs [13]. Nevertheless, whether and how $\sigma \mathrm{R} 1$ is involved in signal processing of GCs is still largely unknown.

In the present work, using patch-clamp techniques, we found that the $\sigma \mathrm{R} 1$ agonist SKF10047 (SKF) suppressed NMDA receptor-, but not $\alpha$-amino-3-hydroxy-5methyl-4-isoxazolepropionic acid (AMPA) receptor-, mediated light-evoked excitatory postsynaptic currents (eEPSCs) of ON, OFF and ON-OFF GCs. Furthermore, SKF did not influence miniature EPSCs (mEPSCs) of GCs, suggesting that the effect of SKF was mediated by a direct action of this agonist on $\sigma \mathrm{R} 1$ expressed on rat GCs.

\section{Materials and Methods}

\section{Retinal Slice Preparation and Whole Cell Patch-Clamp} Recording

Retinas were prepared from Sprague-Dawley rats ranging in age from P14 to P20, with the day of birth denoted as P0. All efforts were made to minimize the number of animals used and their pain and discomfort in accordance with the National Institute of Health Guide for the Care and Use of Laboratory Animals and the guidelines of Fudan University on the ethical use of animals. Retinal slices were prepared following the procedures reported previously [14] with minor modifications. The eyes were enucleated following deep anesthesia with 0.1-0.2 ml urethane $(25 \mathrm{mg} / \mathrm{ml})$. The posterior eyecups were placed in ice-cold Ringer's for about $1 \mathrm{~min}$ and retinas were then isolated from the sclera. The isolated retinas were cut into 200 - $\mu \mathrm{m}$-thick slices in Ringer's using a manual cutter (ST-20; Narishige, Tokyo, Japan). The slices were transferred into a recording chamber with the cut side up and held mechanically in place by a grid of parallel nylon strings glued onto a U-shape frame of platinum wire, then viewed through a fixed-stage upright microscope (BX51WI; Olympus, Japan) equipped with a $60 \times$ water-immersion ceramic objective and DIC optics. In light stimulation experiments, rats were darkadapted for $3 \mathrm{~h}$ prior to an experiment and retinal slices were prepared under dim red illumination. Other experiments were conducted under room illumination.

Unless otherwise declared, retinal slices were perfused continuously with oxygenated and carbogen-bubbled Ringer's, which contained (in mM) NaCl 125, $\mathrm{KCl} 2.5, \mathrm{CaCl}_{2} 2, \mathrm{MgCl}_{2} 1, \mathrm{NaH}_{2} \mathrm{PO}_{4}$ $1.25, \mathrm{NaHCO}_{3} 25$, glucose 15 , and was warmed up to $32^{\circ} \mathrm{C}$ by an inline heater (TC-324B; Warner, USA).

Whole-cell membrane currents of GCs were recorded with pipettes of 8-10 $\mathrm{M} \Omega$ resistance in voltage-clamp modes filled with a solution containing (in mM) $\mathrm{CsCH}_{3} \mathrm{SO}_{3} 120$, TEA-Cl 10, $\mathrm{CaCl}_{2}$ $0.1, \mathrm{MgCl}_{2}$ 4, EGTA 1, HEPES 10, ATP 3, GTP 0.5, and creatine 12 , pH 7.2 adjusted with $\mathrm{CsOH}$. Drug-containing Ringer's was administrated in bath medium through an inlet by gravity. Pipettes were mounted on a motor-driven micromanipulator (MP285; Sutter, USA), and connected to an EPC10 patch-clamp amplifier (Heka, Germany) for light stimulation experiments or an Axon 700B amplifier (Axon, USA) for recording mEPSCs. Data were acquired at a sampling rate of $5 \mathrm{kHz}$, filtered at $2 \mathrm{kHz}$ and then stored for further analysis. mEPSCs were detected by pClamp
10 (Axon, USA) and analyzed by Mini Analysis Program (Synaptosoft, USA). Events detection was done automatically and occurred when the recorded current showed a rapid excursion from the baseline and reached a preset current threshold. The events recorded during a selected period of $120 \mathrm{~s}$ were averaged for subsequent quantitative analyses.

\section{Light Stimulation}

As previously described [15], voltage steps were used to illuminate an LED mounted on the bottom of the condenser in an Olympus BX51WI microscope. Full-field illumination was focused orthogonally to the main axis of the photoreceptors. Light stimuli of $1 \mu \mathrm{W} / \mathrm{cm}^{2}$ were given for $3 \mathrm{~s}$ at 30 -second intervals. eEPSCs of GCs were examined at holding potentials between -80 and $+40 \mathrm{mV}$ in $20-\mathrm{mV}$ steps.

\section{Identification of GC Subtypes}

Subtypes of GCs were identified based on their responses to light steps [16, 17]. An ON GC responded only to light onset with an inward current, whereas an OFF GC produced an inward current only in response to light offset, and an ON-OFF GC responded to both light onset and offset.

\section{Chemicals}

All chemicals were obtained from Sigma except D-AP5, SKF, NBQX (Tocris). The drugs were stored in frozen stock solution and dissolved in the solution before an experiment. All the lipophilic drugs, such as NBQX, were first dissolved in dimethyl sulfoxide (DMSO) and then added to Ringer's. The final concentration of DMSO was $<0.1 \%$ with no effect on the currents of GCs obtained by whole cell recording.

Statistical Analysis

All data, obtained in cells which were mostly from different retinas, were pooled and presented as mean \pm SEM. Paired Student's $t$ test was used, with values of $p<0.05$ being considered statistically significant.

\section{Results}

\section{SKF Suppresses NMDA Receptor-Mediated}

eEPSCs of GCs

NMDA receptor-mediated eEPSCs of GCs were pharmacologically isolated by adding the AMPA receptor antagonist NBQX $(10 \mu \mathrm{M})$, antagonists of $\mathrm{GABA}_{\mathrm{A}}$ and glycine receptors bicuculline $(10 \mu \mathrm{M})$, strychnine $(10 \mu \mathrm{M})$, and the sodium channel blocker TTX $(0.5 \mu \mathrm{M})$ to bath Ringer's. In the presence of these antagonists, eEPSCs recorded from ON (a), OFF (c) and ON-OFF (e) GCs, all clamped at $-40 \mathrm{mV}$, are respectively shown in figure 1a, $c$, and e. The ON GC responded to the light onset, but not to the offset, with an inward current, and the current, as expected, was almost completely suppressed by the NMDA receptor antagonist D-AP5 (50 $\mu \mathrm{M})$ (fig. 1a). Bath application of $1 \mu \mathrm{M}$ SKF significantly reduced the eEPSC 
Fig. 1. Activation of $\sigma \mathrm{R} 1$ suppresses NMDA receptor-mediated eEPSCs in different types of GCs. a, c, e EPSCs (upper traces) elicited by a 3-second, full-field light stimulus at an intensity of $1 \mu \mathrm{W} / \mu \mathrm{m}^{2}$ from an ON GC (a), OFF GC (c) and ONOFF GC (e), all clamped at $-40 \mathrm{mV}$, were suppressed by $1 \mu \mathrm{M}$ SKF (middle traces). All the currents were completely suppressed by $50 \mu \mathrm{M}$ D-AP5 (lower traces). b, d eEPSCs from ON GCs (b) and OFF GCs (d) exhibited the J-shaped currentvoltage (I-V) relationships that were characteristic of NMDA currents in normal Ringer's (control). SKF of $1 \mu \mathrm{M}$ reduced the eEPSCs at all holding potentials tested, as shown by the I-V curves of eEPSCs obtained in the presence of $1 \mu \mathrm{M}$ SKF. Data points for each cell were normalized to the control eEPSC recorded at $+40 \mathrm{mV}$ and then averaged. $f$ Bar chart summarizing the effects of SKF $(1 \mu \mathrm{M})$ on NMDA receptor-mediated eEPSCs from ON GCs, OFF GCs and ON-OFF GCs clamped at -40 $\mathrm{mV}$. Cell numbers are indicated inside the bars. ${ }^{* *} \mathrm{p}<0.01$.

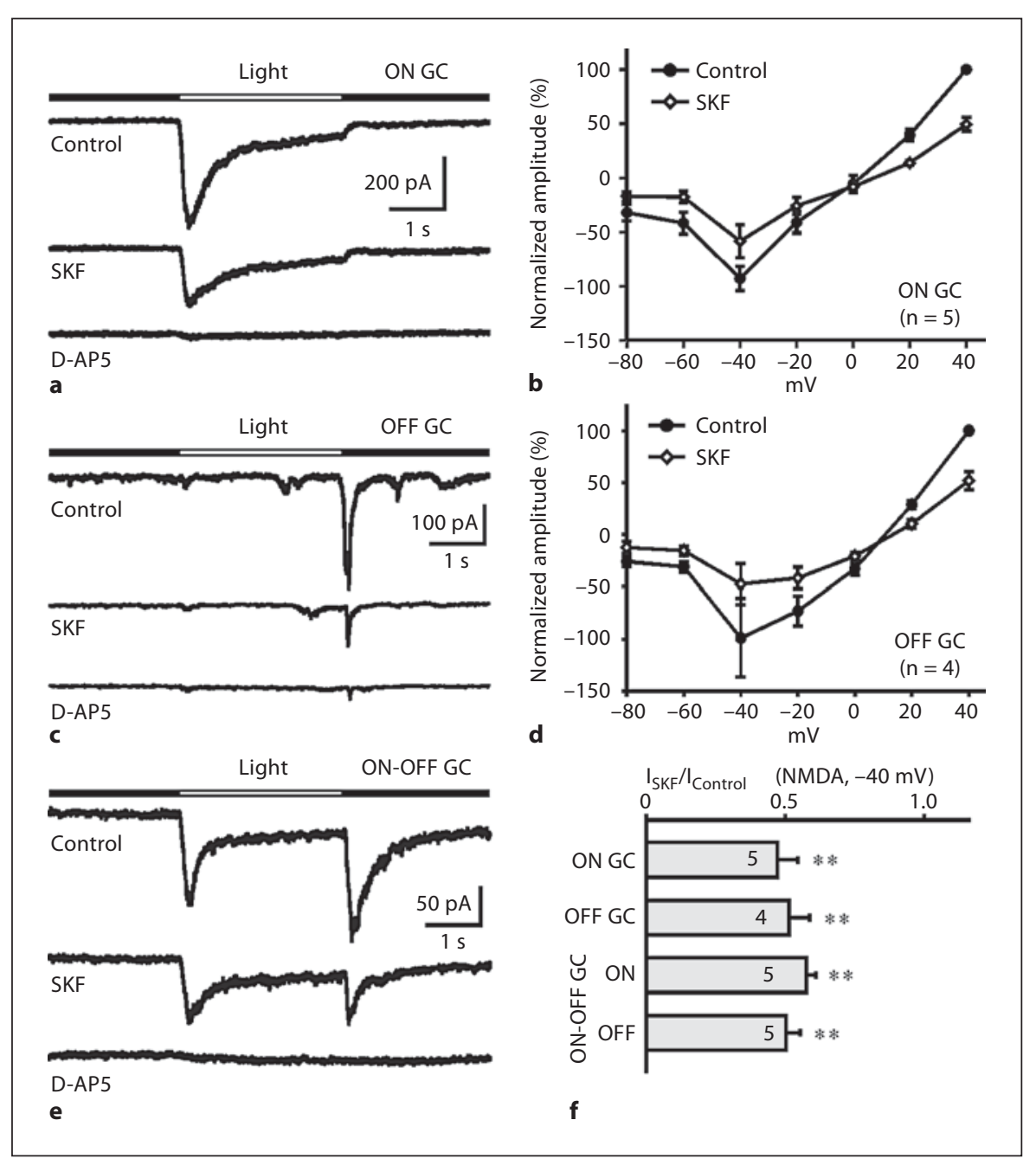

amplitude (from -407.5 to $-206.3 \mathrm{pA}$ ). Similar reductions were observed in four other ON GCs. On average, following the perfusion of $1 \mu \mathrm{M} \mathrm{SKF}$, the eEPSCs were reduced to $47.28 \pm 7.26 \%$ of control $(\mathrm{p}<0.01)$ when the cells were clamped at $-40 \mathrm{mV}$. The relationships of the eEPSCs (I) versus holding potentials $(\mathrm{V})(\mathrm{I}-\mathrm{V})$ of ON GCs $(\mathrm{n}=5)$ obtained before and during SKF application are shown in figure $1 \mathrm{~b}$, and both of them showed a prominent J-shape, indicating the voltage-dependent block of NMDA receptor channels by external $\mathrm{Mg}^{2+}$. It was clear from figure $\mathrm{lb}$ that reductions in eEPSC amplitudes were observed at all holding potentials tested, ranging from -80 to $+40 \mathrm{mV}$.

The effect of SKF on eEPSCs of OFF GCs, which produced an inward current only in response to light offset, was similar. Figure $1 \mathrm{c}$ and $\mathrm{d}$ show the change in the eEPSC of an OFF GC and that in the average I-V relationship of GC eEPSCs $(n=4)$ after SKF application, respec- tively. SKF of $1 \mu \mathrm{M}$ produced considerable decreases in eEPSC amplitudes at different holding potentials. At -40 $\mathrm{mV}$, the eEPSCs were reduced to $48.69 \pm 7.35 \%$ of control $(\mathrm{p}<0.01)$ by SKF perfusion.

Similarly, application of $1 \mu \mathrm{M}$ SKF greatly suppressed both $\mathrm{ON}$ and OFF components of the ON-OFF GC eEPSC (fig. 1e), with an average suppression of $42.43 \pm$ $3.28 \%$ for ON components and of $49.60 \pm 4.83 \%$ for OFF components respectively $\left(\mathrm{n}=5, \mathrm{p}<0.01, \mathrm{~V}_{\text {hold }}=-40 \mathrm{mV}\right)$. The reductions of eEPSCs obtained at $-40 \mathrm{mV}$ in the ON, OFF and ON-OFF GCs due to application of $1 \mu \mathrm{M}$ SKF are shown in figure if for comparison.

SKF-induced suppression of eEPSCs could be blocked by BD1047, a $\sigma \mathrm{R} 1$ antagonist. We first perfused the preparations with $10 \mu \mathrm{M}$ BD1047 for $8 \mathrm{~min}$ and then observed effects of $1 \mu \mathrm{M}$ SKF on NMDA receptor-mediated eEPSCs of ON, OFF and ON-OFF GCs clamped at -40 
Fig. 2. BD1047 blocks the suppression effects of SKF on NMDA receptor-mediated eEPSCs of GCs, clamped at $-40 \mathrm{mV}$. With pre-incubation of $10 \mu \mathrm{M}$ BD1047, $1 \mu \mathrm{M}$ SKF failed to suppress the eEPSCs of an $\mathrm{ON}(\mathbf{a}), \mathrm{OFF}$ (b) and ON-OFF GC (c).


Fig. 3. SKF does not change AMPA receptor-mediated eEPSCs in different types of GCs clamped at $-70 \mathrm{mV}$. a-c $1 \mu \mathrm{M}$ SKF had no effects on the eEPSCs of an ON (a), OFF (b) and ON-OFF GC (c). d Bar chart summarizing the effects of SKF $(1 \mu \mathrm{M})$ on AMPA receptor-mediated eEPSCs from ON GCs, OFF GCs, and ON-OFF GCs. Cell numbers are indicated inside the bars.
$\mathrm{mV}$. As shown in figure $2 \mathrm{a}-\mathrm{c}$, following pre-incubation with $10 \mu \mathrm{M}$ BD1047, perfusion of $1 \mu \mathrm{M}$ SKF failed to suppress the eEPSCs, and the eEPSCs recorded in the presence of $1 \mu \mathrm{M}$ SKF were $98.89 \pm 4.67 \%$ of control $(n=10$, $\mathrm{p}>0.05$ ) for ON components and $93.10 \pm 4.41 \%$ of control $(n=5, p>0.05)$ for OFF components. Here, data from $\mathrm{ON}$, OFF and ON-OFF GCs were pooled for statistical analysis.

\section{SKF Has No Effects on AMPA Receptor-Mediated} GC eEPSCs

There is evidence that AMPA receptors mainly mediate non-NMDA excitatory synaptic responses of both ON and OFF GCs $[16,18]$. Effects of SKF on AMPA receptormediated eEPSCs of GCs were further tested. AMPA receptor-mediated eEPSCs of GCs were pharmacologically isolated by adding D-AP5 $(50 \mu \mathrm{M})$, bicuculline $(10 \mu \mathrm{M})$, strychnine $(10 \mu \mathrm{M})$, and TTX $(0.5 \mu \mathrm{M})$ to bath Ringer's. In the presence of these antagonists eEPSCs recorded from ON, OFF and ON-OFF GCs, clamped at $-70 \mathrm{mV}$, are respectively shown in the left panel of figure $3 a-c$. Unlike NMDA receptor-mediated eEPSCs, the I-V curves of AMPA receptor-mediated eEPSCs became linear [16] (data not shown). As shown in the right panel of figure $3 \mathrm{a}-\mathrm{c}$, bath application of $1 \mu \mathrm{M}$ SKF hardly changed the AMPA receptor-mediated eEPSCs of these cells. The relative eEPSC amplitudes were $98.20 \pm 2.15 \%$ of control $(\mathrm{n}=5, \mathrm{p}>0.05)$ for ON GCs; $97.53 \pm 1.79 \%$ of control $(\mathrm{n}=4, \mathrm{p}>0.05)$ for OFF GCs; $97.09 \pm 1.92 \%$ of control $(\mathrm{n}=4, \mathrm{p}>0.05)$ for ON components, and $91.77 \pm 4.44 \%$ of control $(\mathrm{n}=4, \mathrm{p}>0.05)$ for OFF components of ONOFF GCs, respectively (fig. $3 \mathrm{~d}$ ).

\section{mEPSCs of GCs Were Not Affected by SKF}

To test whether the suppression effect of SKF might be a consequence of possible changes in glutamate release of bipolar cells, which are presynaptic to GCs, we studied effects of SKF on the mEPSC of GCs that is a reflection 


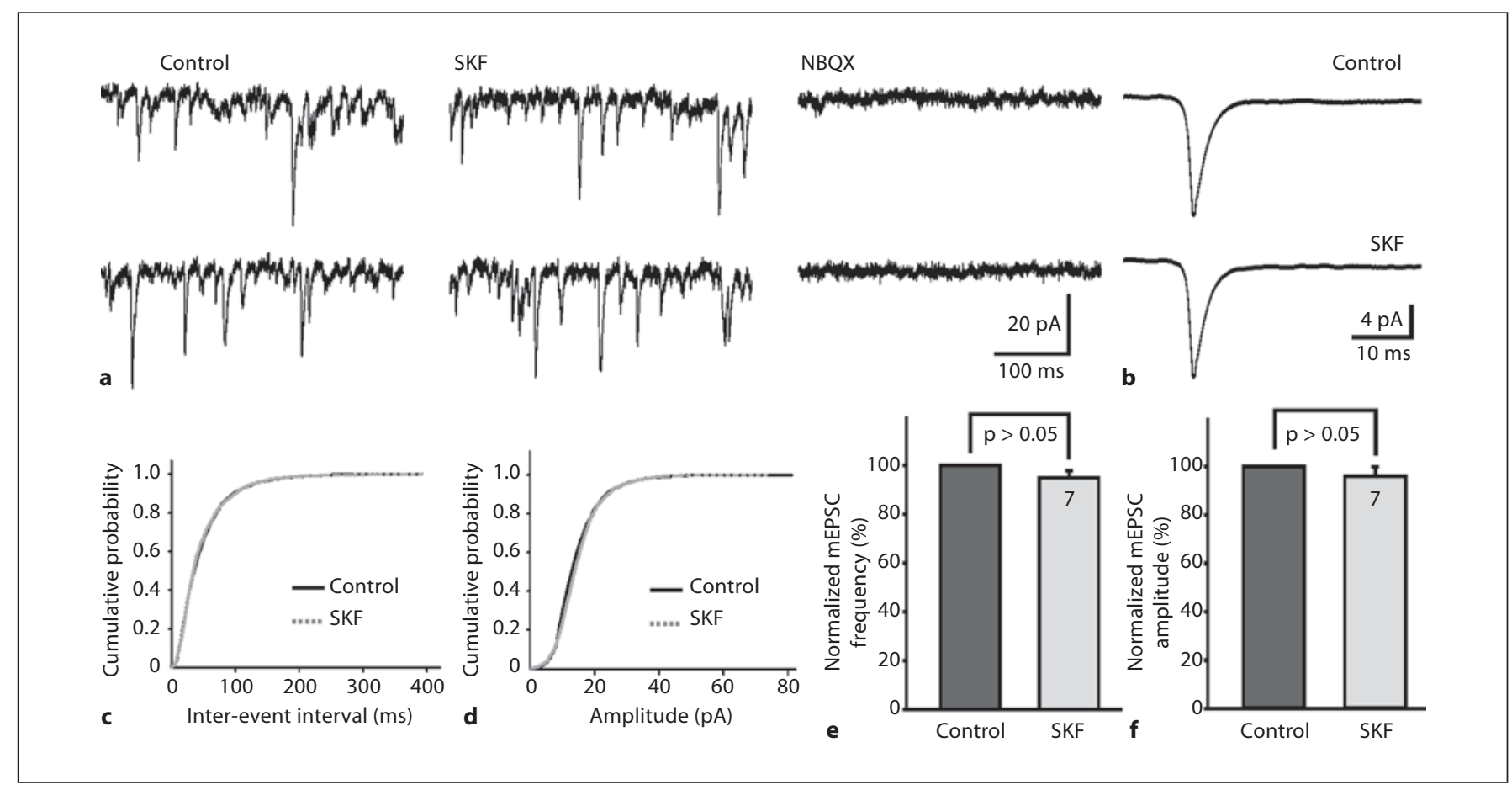

Fig. 4. mEPSCs of GCs are not affected by SKF. a Representative mEPSC recordings of a GC in normal Ringer's (left two traces), in the presence of $1 \mu \mathrm{M}$ SKF (middle two traces) or $10 \mu \mathrm{M} \mathrm{NBQX}$ (right two traces), respectively. Note that the mEPSCs were blocked by NBQX and SKF had no effect on the mEPSCs. b Averaged mEPSCs waveforms derived from events recorded during $120 \mathrm{~s}$ in normal Ringer's (control) and in the presence of $1 \mu \mathrm{MSKF}$ from the same cell as shown in a, demonstrating no change in kinetics of mEPSCs following SKF application. c, d Cumulative distributions for inter-event interval (c) and amplitude (d) of mEPSCs obtained from the cell shown in a. No changes in these curves were found. e, f Bar graphs summarizing the effects of $1 \mu \mathrm{M}$ SKF on frequencies (e) and amplitudes (f) of GC mEPSCs. All data for each cell were normalized to control and then averaged. of the spontaneous release of glutamate from bipolar cells. For these experiments, bicuculline $(10 \mu \mathrm{M})$, strychnine $(10 \mu \mathrm{M})$ and TTX $(0.5 \mu \mathrm{M})$ were added to Ringer's to isolate mEPSCs of GCs. Figure 4a shows the representative mEPSC recording from a GC voltage-clamped at $-70 \mathrm{mV}$ (left two traces). The currents were completely blocked by application of $10 \mu \mathrm{M}$ NBQX (right two traces), indicating that they were solely mediated by AMPA receptors. Application of SKF $(1 \mu \mathrm{M})$ did not significantly change the mEPSCs (fig. $4 \mathrm{a}$, middle two traces). Additionally, as shown in figure $4 \mathrm{~b}$, the average mEPSC derived from the events recorded during $120 \mathrm{~s}$ in $1 \mu \mathrm{M}$ SKFcontaining Ringer's (lower trace) was unchanged in kinetics after SKF perfusion, as compared to the control response (upper trace). Furthermore, the cumulative probability distribution curves of inter-event intervals and amplitudes of these events recorded in the presence of $1 \mu \mathrm{M}$ SKF did not show any shift, as compared to those in normal Ringer's (control), indicating little change in frequency and amplitude (fig. 4c, d). Similar results were obtained in six other GCs. Neither average frequency nor amplitude of mEPSCs were significantly changed in the presence of SKF $(98.36 \pm 4.17 \%$ of control for frequency and $105.54 \pm 5.01 \%$ of control for amplitude, $n=5, p>$ $0.05)$ (fig. $4 \mathrm{e}, \mathrm{f}$ ).

\section{Discussion}

Three types of ionotropic glutamate receptor subtypes, NMDA, AMPA and kainite receptors, are all expressed on GCs [19-24]. Since NMDA receptors may be located extrasynaptically and activated only by the concomitant release of many synaptic vesicles [25], they are thought to contribute, along with AMPA receptors, mainly to light-/electrically evoked EPSCs of these cells $[16,18]$, but much less to spontaneous EPSCs [25]. Meanwhile, kainite receptors contribute little direct synaptic current to eEPSCs [18]. In this work we demonstrated that SKF preferentially suppressed NMDA receptor-, but not 
AMPA receptor-, mediated eEPSCs of rat ON, OFF and ON-OFF GCs. This is similar to that observed in mouse cultured hippocampal pyramidal neurons, in which $\sigma$ binding site ligands attenuated NMDA, but not AMPA, evoked currents [26]. This effect of SKF could be blocked by application of BD-1047, suggesting the involvement of $\sigma R 1$. It is likely that $\sigma \mathrm{R} 1$ is indeed involved in photic signaling of rat GCs. It is of interest to note that in primate GCs the blockade of NMDA receptors tends to result in a more transient light response of these cells [27], which could be mainly mediated by AMPA receptors [16]. It therefore implies that activation of $\sigma \mathrm{R} 1$ may change the kinetics of light responses of rat GCs by preferentially suppressing NMDA receptor-mediated eEPSCs.

Under our experimental conditions, mEPSCs of rat GCs that are mainly produced by spontaneous glutamate release from bipolar cells could be completely suppressed by NBQX (fig. 4a), suggesting that these events were exclusively mediated by AMPA receptors. It has been documented that spontaneous EPSCs of GCs are largely contributed by AMPA receptors [28-30]. While it has been reported that the activation of $\sigma \mathrm{R} 1$ increases the frequency of mEPSCs of immature hippocampal neurons [31, 32] and of prelimbic cortical neurons [33], the present work showed that application of SKF affected neither frequency nor amplitude of the mEPSC of rat GCs, meaning no effects of SKF on spontaneous glutamate release of bipolar cells. This may be due to the fact that all rat bipolar cells do not express $\sigma \mathrm{R} 1$, as revealed by a recent immunocytochemical study [6]. It seems likely that the
SKF-induced suppression of NMDA receptor-mediated eEPSCs may be a consequence of SKF-induced activation of $\sigma \mathrm{R} 1$ in GCs. Actually, in pharmacologically isolated rat GCs, we recently reported that activation of $\sigma \mathrm{R} 1$ by SKF or PRE-084 suppressed NMDA receptor-mediated current responses [13].

Although endogenous ligands for $\sigma \mathrm{R} 1$ are not yet clearly identified, it is generally thought that neurosteroids may be the most plausible candidates [34, 35]. In the retina, neurosteroids are synthesized by specific types of retinal cells, and metabolized via the blood-circulating system [36]. Moreover, there are several studies reporting that neurosteroids protect retinal tissue against ischemia/ reperfusion damage, in which $\sigma \mathrm{R} 1$ may be involved [37, 38]. It has also been reported that some neurosteroids significantly affect NMDA receptor-mediated responses in GCs [39] and modulate retinal GABAergic neurotransmission and electroretinographic activity [40]. What types of retinal neurons may secrete neurosteroids and how these steroids act on $\sigma \mathrm{R} 1$ expressed on GCs may be worthwhile exploring further.

\section{Acknowledgements}

This work was supported by grants from the National Program of Basic Research sponsored by the Ministry of Science and Technology of China (2006CB500805, 2007CB512205, 2011CB504602), the National Natural Science Foundation of China $(30770698,30930634,31070967)$, and the 211 Project sponsored by the Ministry of Education of China.

\section{References}

1 Hayashi T, Su T: The sigma receptor: evolution of the concept in neuropsychopharmacology. Curr Neuropharmacol 2005;3:267280.

-2 Quirion R, Bowen WD, Itzhak Y, Junien JL, Musacchio JM, Rothman RB, Su TP, Tam SW, Taylor DP: A proposal for the classification of sigma binding sites. Trends Pharmacol Sci 1992;13:85-86.

3 Myers AM, Charifson PS, Owens CE, Kula NS, McPhail AT, Baldessarini RJ, Booth RG, Wyrick SD: Conformational analysis, pharmacophore identification, and comparative molecular field analysis of ligands for the neuromodulatory $\sigma_{3}$ receptor. J Med Chem 1994;37:4109-4117.
-4 Booth RG, Owens CE, Brown RL, Bucholtz EC, Lawler CP, Wyrick SD: Putative $\sigma_{3}$ sites in mammalian brain have histamine $\mathrm{H}_{1}$ receptor properties: Evidence from ligand binding and distribution studies with the novel $\mathrm{H}_{1}$ radioligand $\left[{ }^{3} \mathrm{H}\right]-(-)$-trans-1-phenyl-3-aminotetralin. Brain Res 1999;837:95105.

5 Maurice T, Su TP: The pharmacology of sigma-1 receptors. Pharmacol Ther 2009;124: 195-206.

6 6 Liu LL, Wang L, Zhong YM, Yang XL: Expression of sigma receptor $1 \mathrm{mRNA}$ and protein in rat retina. Neuroscience 2010;167: 1151-1159.

7 Ola MS, Moore P, El-Sherbeny A, Roon P, Agarwal N, Sarthy VP, Casellas P, Ganapathy V, Smith SB: Expression pattern of sigma receptor $1 \mathrm{mRNA}$ and protein in mammalian retina. Brain Res Mol Brain Res 2001;95: 86-95.
-8 Dun Y, Thangaraju M, Prasad P, Ganapathy V, Smith SB: Prevention of excitotoxicity in primary retinal ganglion cells by $(+)$-pentazocine, a sigma receptor-1 specific ligand. Invest Ophthalmol Vis Sci 2007;48:4785-4794.

-9 Martin PM, Ola MS, Agarwal N, Ganapathy V, Smith SB: The sigma receptor ligand (+)-pentazocine prevents apoptotic retinal ganglion cell death induced in vitro by homocysteine and glutamate. Brain Res $\mathrm{Mol}$ Brain Res 2004;123:66-75.

10 Tchedre KT, Yorio T: Sigma-1 receptors protect RGC-5 cells from apoptosis by regulating intracellular calcium, Bax levels, and caspase- 3 activation. Invest Ophthalmol Vis Sci 2008;49:2577-2588.

11 Cantarella G, Bucolo C, Di Benedetto G, Pezzino S, Lempereur L, Calvagna R, Clementi $\mathrm{S}$, Pavone P, Fiore L, Bernardini R: Protective effects of the sigma agonist Pre-084 in the rat retina. Br J Ophthalmol 2007;91:1382-1384. 
-12 Senda T, Mita S, Kaneda K, Kikuchi M, Akaike A: Effect of SA4503, a novel $\sigma_{1}$ receptor agonist, against glutamate neurotoxicity in cultured rat retinal neurons. Eur J Pharmacol 1998;342:105-111.

13 Zhang XJ, Liu LL, Jiang SX, Zhong YM, Yang $\mathrm{XL}$ : Activation of the sigma receptor 1 suppresses NMDA responses in rat retinal ganglion cells. Neuroscience 2011;177:12-22.

14 Chen L, Yang XL: Hyperpolarization-activated cation current is involved in modulation of the excitability of rat retinal ganglion cells by dopamine. Neuroscience 2007;150: 299-308.

15 Zhao WJ, Zhang M, Miao Y, Yang XL, Wang Z: Melatonin potentiates glycine currents through a PLC/PKC signalling pathway in rat retinal ganglion cells. J Physiol 2010;588: 2605-2619.

$\checkmark 16$ Cohen ED: Light-evoked excitatory synaptic currents of X-type retinal ganglion cells. J Neurophysiol 2000;83:3217-3229.

17 Kalbaugh TL, Zhang J, Diamond JS: Coagonist release modulates NMDA receptor subtype contributions at synaptic inputs to retinal ganglion cells. J Neurosci 2009;29:14691479.

18 Jacoby RA, Wu SM: AMPA-preferring receptors mediate excitatory non-NMDA responses of primate retinal ganglion cells. Vis Neurosci 2001;18:703-710.

19 Sucher NJ, Kohler K, Tenneti L, Wong HK, Grunder T, Fauser S, Wheeler-Schilling T, Nakanishi N, Lipton SA, Guenther E: Nmethyl-D-aspartate receptor subunit NR3A in the retina: developmental expression, cellular localization, and functional aspects. Invest Ophthalmol Vis Sci 2003;44:4451-4456.

20 Grunert U, Haverkamp S, Fletcher EL, Wassle $\mathrm{H}$ : Synaptic distribution of ionotropic glutamate receptors in the inner plexiform layer of the primate retina. J Comp Neurol 2002;447:138-151.
1 Lin B, Martin PR, Grunert U: Expression and distribution of ionotropic glutamate receptor subunits on parasol ganglion cells in the primate retina. Vis Neurosci $2002 ; 19$ : 453-465.

22 Peng YW, Blackstone CD, Huganir RL, Yau KW: Distribution of glutamate-receptor subtypes in the vertebrate retina. Neuroscience 1995;66:483-497.

23 Zhang CX, Hammassaki-Britto DE, Britto LRG, Duvoisin RM: Expression of glutamate receptor subunit genes during development of the mouse retina. Neuroreport 1996;8: 335-340.

24 Brandstatter JH, Koulen P, Wassle H: Diversity of glutamate receptors in the mammalian retina. Vision Res 1998;38:1385-1397.

25 Chen S, Diamond JS: Synaptically released glutamate activates extrasynaptic NMDA receptors on cells in the ganglion cell layer of rat retina. J Neurosci 2002;22:2165-2173.

26 Fletcher EJ, Church J, Abdel-Hamid K, MacDonald JF: Blockade by sigma site ligands of $\mathrm{N}$-methyl-D-aspartate-evoked responses in rat and mouse cultured hippocampal pyramidal neurones. Br J Pharmacol 1995;116: 2791-2800.

27 Cohen ED, Miller RF: The role of NMDA and non-NMDA excitatory amino acid receptors in the functional organization of primate retinal ganglion cells. Vis Neurosci 1994;11: 317-332.

28 Taylor WR, Chen E, Copenhagen DR: Characterization of spontaneous excitatory synaptic currents in salamander retinal ganglion cells. J Physiol 1995;486:207-221.

29 Zhang J, Diamond JS: Subunit- and pathwayspecific localization of NMDA receptors and scaffolding proteins at ganglion cell synapses in rat retina. J Neurosci 2009;29:42744286

30 Sagdullaev BT, McCall MA, Lukasiewicz PD: Presynaptic inhibition modulates spillover, creating distinct dynamic response ranges of sensory output. Neuron 2006;50:923-935.

- 31 Meyer DA, Carta M, Partridge LD, Covey DF, Valenzuela CF: Neurosteroids enhance spontaneous glutamate release in hippocampal neurons. Possible role of metabotropic $\sigma_{1}$-like receptors. J Biol Chem 2002;277: 28725-28732.
32 Mameli M, Carta M, Partridge LD, Valenzuela CF: Neurosteroid-induced plasticity of immature synapses via retrograde modulation of presynaptic NMDA receptors. J Neurosci 2005;25:2285-2294.

33 Dong Y, Fu YM, Sun JL, Zhu YH, Sun FY, Zheng P: Neurosteroid enhances glutamate release in rat prelimbic cortex via activation of $\alpha_{1}$-adrenergic and $\sigma_{1}$ receptors. Cell Mol Life Sci 2005;62:1003-1014.

34 Baulieu EE: Neurosteroids: a novel function of the brain. Psychoneuroendocrinology 1998;23:963-987.

35 Maurice T, Gregoire C, Espallergues J: Neuro(active)steroid actions at the neuromodulatory $\sigma_{1}$ receptor: biochemical and physiological evidence, consequences in neuroprotection. Pharmacol Biochem Behav 2006;84:581-597.

36 Guarneri P, Cascio C, Russo D, D’Agostino S, Drago G, Galizzi G, De Leo G, Piccoli F, Guarneri M, Guarneri R: Neurosteroids in the retina: neurodegenerative and neuroprotective agents in retinal degeneration. Ann N Y Acad Sci 2003;1007:117-128

37 Bucolo C, Drago F: Effects of neurosteroids on ischemia-reperfusion injury in the rat retina: role of $\sigma_{1}$ recognition sites. Eur J Pharmacol 2004;498:111-114.

38 Bucolo C, Drago F: Neuroactive steroids protect retinal tissue through $\sigma_{1}$ receptors. Basic Clin Pharmacol Toxicol 2007;100:214-216.

39 Guarneri P, Russo D, Cascio C, De Leo G, Piccoli T, Sciuto V, Piccoli F, Guarneri R: Pregnenolone sulfate modulates NMDA receptors, inducing and potentiating acute excitotoxicity in isolated retina. J Neurosci Res 1998;54:787-797.

-40 Jaliffa CO, Howard S, Hoijman E, Salido E, Sarmiento MI, Arias P, Rosenstein RE: Effect of neurosteroids on the retinal gabaergic system and electroretinographic activity in the golden hamster. J Neurochem 2005;94:16661675. 